\title{
OBSERVATORIO
}

\section{RASGOS Y TRAYECTORIAS DE LA DOCUMENTACIÓN AUDIOVISUAL: LOGROS, RETOS Y QUIMERAS}

\section{Eugenio López-de-Quintana-Sáenz}

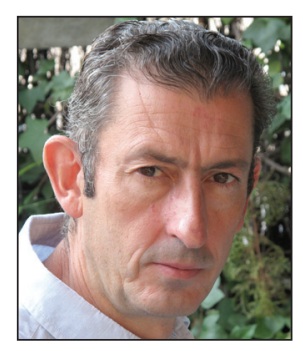

Eugenio López-de-Quintana-Sáenz, Madrid, 1960, es director de Documentación en Atresmedia. Ha colaborado como docente con las universidades Carlos III de Madrid, Complutense y otras instituciones académicas. Ha sido miembro del comité ejecutivo de la Federación Internacional de Archivos de Televisión (FIAT) y presidente de la Asociación Española de Documentación e Información (Sedic). Es autor de varios trabajos, ponencias y conferencias en eventos nacionales e internacionales.

http://orcid.org/0000-0002-8263-6875

Antena 3TV, SA Isla Graciosa, s/n

\section{Resumen} 28700 San Sebastián de los Reyes, Madrid, España elopez@antena3tv.es

Aunque muchos archivos audiovisuales están todavía a la espera de un proyecto de digitalización de sus fondos analógicos que garantice su preservación y favorezca el acceso público, se asiste a una generación masiva de contenidos audiovisuales que ha completado ya la transición hacia la digitalización de todo el proceso de producción y distribución. Las exigencias de una producción cada vez más diversificada llevan a priorizar la recuperación de planos en los archivos, y se buscan alternativas automáticas de extracción de metadatos, indexación y búsqueda, que sin embargo no evitan la utilización de información textual para la descripción de imágenes. El tratamiento documental de imágenes es una tarea extremadamente costosa en recursos humanos, con tiempos de dedicación de dos, tres o incluso más veces la duración del material tratado. En paralelo, grandes volúmenes de contenidos audiovisuales son indexados en origen, al margen de los circuitos profesionales de gestión documental. Se acentúa así la tendencia anunciada hacia una transformación de las tareas tradicionales de los documentalistas, que está experimentando una menor hibridación de la esperada con otros colectivos del sector.

\section{Palabras clave}

Documentación audiovisual, Archivos audiovisuales, Archivos de televisión, Producción audiovisual, Digitalización, Documentalistas, Profesionales, Catalogación, Recuperación de información, España.

Title: Traits and trajectories of audiovisual documentation: achievements, challenges and chimeras

\begin{abstract}
Although many analogic audiovisual archives are still awaiting a digitization project that guarantees their preservation and public access, a massive generation of audiovisual content is taking place, once the source has completed the transition to digital production and distribution. The demand for an increasingly diversified production at TV stations is leading to the need to prioritize image retrieval from the archives for reuse. Efficient alternatives for automatic metadata extraction, indexing and searching are sought, and text information to describe images continues to be necessary. The documentary image processing is extremely costly in human resources, with dedication times of two, three or even more times the length of the treated material. In parallel, part of the audiovisual production is indexed during the production process by people other than archivists, librarians or information scientists. Therefore, a transformation of the traditional tasks carried out by the above mentioned professionals is becoming more evident; on the other hand, these professionals continue to be isolated and less hybridized than expected with other labor profiles.
\end{abstract}

\section{Keywords}

Audiovisual documentation, Audiovisual archives, Television archives, Audiovisual production, Digitization, Information managers, Librarians, Profession, Cataloging, Information retrieval, Spain.

López-de-Quintana-Sáenz, Eugenio (2014). “Rasgos y trayectorias de la documentación audiovisual: logros, retos y quimeras". El profesional de la información, enero-febrero, v. 23, n. 1, pp. 5-12.

http://dx.doi.org/10.3145/epi.2014.ene.01 


\section{Introducción}

En el observatorio que El profesional de la información publicó a finales de 2007 (López-de-Quintana-Sáenz, 2007) se presentaba una fase de transición en la que la documentación audiovisual se dirigía hacia la completa integración en sistemas globales de producción digital, experimentando en el camino una transformación de la identidad de los profesionales de este sector por la pérdida en parte de sus tradicionales funciones que les caracterizan, pero también por la versatilidad de las nuevas herramientas a disposición de la gestión documental. Todo ello tenía lugar en un escenario empresarial de producción audiovisual polarizado entre los grandes y minoritarios operadores televisivos y las pequeñas y mayoritarias pymes del sector.

Casi seis años después, al comienzo del que parece un esperanzador 2014 y en los coletazos de un período de crisis generalizada en todos los sectores de la economía, se revisa la situación de la documentación audiovisual desde cuatro puntos de vista y con algunas referencias específicas a España:

- transición digital de los sistemas de producción;

- digitalización retrospectiva;

- sistemas de tratamiento y búsqueda de imágenes;

- situación de los profesionales del sector.

Los operadores de televisión, por compleja que fuera su estructura tecnológica previa, han completado sus procesos de conversión a sistemas digitales de producción

\section{El entorno tapeless, una realidad en todos los niveles de producción}

En estos años todos los operadores de televisión, por compleja que fuera su estructura tecnológica previa, han completado sus procesos de conversión a sistemas digitales de producción. Sofisticados sistemas de redacción electrónica, edición no lineal y emisión digital conviven integrados en los nuevos MAM (media asset management) o DAM (digital asset management), mucho más consolidados ahora que en las versiones iniciales de la primera fase de la digitalización. Sin embargo, estas siglas presentan todavía un cierto grado de ambigüedad y son poco conocidas, probablemente por pertenecer a un sector muy específico de la industria audiovisual, y dentro de ésta sólo a aquellas organizaciones que desarrollan toda la cadena de producción y emisión de contenidos en el sentido más extenso.

Los MAM o DAM son complejas soluciones de software capaces de integrar tanto otras piezas de software como diversos dispositivos de hardware con los que administrar el proceso completo de la producción, emisión y archivo de contenidos audiovisuales, y en las que "el flujo es un concepto tan importante como la información en sí misma" (Lizarralde, 2009). Sin embargo, y pese a la posibilidad de introducción de metadatos asociados a los ficheros de video en todas las fases de este proceso de producción, la incorporación de las funciones propias de la gestión documental en los MAM o DAM no ha tenido una trayectoria definida ni unos resultados homogéneos. En general podemos decir que los productos comerciales han venido ofreciendo, con las excepciones correspondientes, un sorprendente nivel de carencias respecto a las funciones con las que se venían gestionando los archivos de televisión en el mundo analógico.

La implantación de sistemas de MAM ha sido variada en nuestro país, desde la compra de productos llave en mano como es el caso de Televisión Española (TVE) con el sistema Tarsys, de Tedial, hasta desarrollos internos como los realizados por Euskal Telebista (ETB) o Televisió de Catalunya (Conesa, 2013). Una opción diferente es la adoptada por Antena 3 Televisión, que además de elaborar su propio $M A M$, el $S G A$, ha creado el software específico Gama para la gestión documental de activos digitales, que puede operar con otros sistemas comerciales del mercado (López-deQuintana-Sáenz, 2013).

Sin duda otro de los elementos clave para la digitalización de la producción audiovisual ha sido la evolución de los sistemas de almacenamiento. En las grandes estructuras de producción, donde diariamente se desencadenan miles de operaciones de movimiento de imágenes entre dispositivos, y cuyos fondos documentales son de gran envergadura, se han impuesto con rotundidad políticas basadas en tres tipos de almacenamientos combinados entre sí:

- espacios de trabajo sobre disco con capacidad para varios miles de horas en alta calidad (almacenamiento online);

- poderosas librerías de archivo digital sobre cintas de datos de capacidad unitaria superior a 1,5 TB y capacidad total de archivo de centenares de miles de horas (almacenamiento nearline);

- una capa de almacenamiento en baja resolución generada automáticamente a partir del material original y utilizada para el visionado y la edición offline.

A menor escala la digitalización se resuelve con similares aplicaciones para el mundo profesional, o incluso para el mercado doméstico. Uno de los sistemas de edición más extendido en los últimos años en las productoras audiovisuales ha sido Final Cut, orientado al mercado profesional hasta 2013 pero ahora dirigido ya sólo al gran público con el producto Final Cut Pro $X$, mientras que el hueco dejado en la edición profesional a pequeña escala lo va ocupando Adobe Premiere. Con estos niveles de producción y archivo las necesidades de almacenamiento quedan sobradamente cubiertas con servidores online en RAID sin necesidad de recurrir a librerías digitales y cintas de datos. Sin embargo, es muy habitual que en la práctica las opciones de almacenamiento se limiten a la acumulación en memorias de almacenamiento externo o incluso soportes de grabación como el Xdcam a la espera de soluciones más sofisticadas.

Del mismo modo es frecuente que a este nivel exista cierta precariedad en el uso de herramientas de gestión documental. En los casos en que esta función exista como tal, las necesidades se resuelven con aplicaciones de ofimática o, en el mejor de los casos, con bases de datos no especializadas y que no ofrecen las posibilidades de gestión y visualización de contenidos de los sistemas profesionales. 


\section{Digitalización retrospectiva y acceso público, una asignatura pendiente}

Como es bien sabido, el término digitalización no sólo se refiere al cambio tecnológico en la producción de contenidos, sino a la transferencia de contenidos desde sus soportes analógicos originales a un formato digital. Sin embargo, si bien en el primer caso la oferta del mercado arrastra a las organizaciones en la evolución digital, no ocurre así con los ingentes volúmenes de información que estas organizaciones han heredado de la fase tecnológica anterior.

Mientras las empresas modernizan sus infraestructuras por la marcha inexorable del cambio tecnológico, los archivos audiovisuales analógicos quedan a la espera de proyectos específicos de recuperación costosos en inversión, tiempo y recursos humanos. Esta espera puede resultar muy perjudicial para la preservación y la legibilidad de estos soportes, especialmente si se trata de grabaciones en video. La experiencia está demostrando, por ejemplo, que los archivos en cintas Betacam SP de finales de los años 80 y comienzos de los 90 empiezan a mostrar signos irreparables de desgaste.

La situación en España no es muy alentadora a este respecto. En los últimos años se ha conseguido llevar adelante proyectos de gran relevancia tanto por el valor de los contenidos como por su volumen, pero en paralelo no existe un proyecto nacional de recuperación de los pequeños archivos que se encuentran dispersos por toda la geografía en posesión de organizaciones, empresas o particulares.

Entre los proyectos más relevantes está sin duda la digitalización de los fondos del No-Do, que más allá de su utilización original como propaganda política se han convertido en una "fuente única de imágenes sobre la vida en España entre los años 1940 y 1970" (De-Prado, 2013). Se trata de un proyecto en colaboración entre Filmoteca española y Radio Televisión Española (RTVE) para la digitalización de las bobinas, que años antes ya habían sido transferidos a cintas $B e-$ tacam SP para facilitar su comercialización. A finales de 2012 el proyecto fue presentado al público haciendo accesibles en internet 700 horas de video. Entre marzo y octubre de 2013 se registraron más de 1,5 millones de accesos con un tiempo medio de consulta de 6,30 minutos (De-Prado, 2013).

RTVE está llevando a cabo en colaboración con Telefónica el proyecto de digitalización de fondos audiovisuales de mayor envergadura en España. Tras una primera fase de conversión de formatos más antiguos como cine, $U$-matic y 1 y 2 pulgadas a nuevos formatos de video, iniciada en 2002, en 2009 comenzó la digitalización propiamente dicha. Según la información proporcionada por los responsables del proyecto, de los 2.680 .000 soportes censados en $2011,1.430 .000$ soportes es el fondo potencial a digitalizar descontando copias, de los cuales a finales de febrero de 2014 deberían estar ya digitalizados entre 350.000 y 400.000. Los criterios de selección han sido su estado de conservación, su importancia histórica y su posible explotación comercial. El trabajo se realiza con medios internos de RTVE y mediante contratación de empresas externas, pero una vez finalizada la fase inicial en 2014, RTVE continuará digitalizando con medios propios. Desde el inicio del proyecto se ha aprovechado para revisar el tratamiento documental, y el compromiso es hacer visibles los fondos en internet a medida que se van digitalizando.

\section{Mientras las empresas modernizan sus infraestructuras, los archivos audiovi- suales analógicos quedan a la espera de costosos proyectos de recuperación}

Además de RTVE, otras cadenas de televisión como Antena 3, Telecinco y varias cadenas autonómicas dentro de la Federación de Organismos o Entidades de Radio y Televisión Autonómicos (Forta) están llevando a cabo la digitalización de sus archivos. Una situación singular por su dramatismo es el de la Radio Televisión Valenciana (RTVV), ya que tras su reciente cierre se abren muchos interrogantes sobre la preservación de sus fondos acumulados durante más de 24 años de emisión. La conservación de estos fondos, sólo digitalizados parcialmente (Alfonso-Noguerón, 2009), presenta retos técnicos inéditos en nuestro país en el ámbito audiovisual. Por un lado los soportes analógicos necesitan ser conservados en condiciones ambientales específicas con su correspondiente coste de mantenimiento, pero además han iniciado ya su particular cuenta atrás en el proceso de degradación física que aconseja su digitalización. Por su parte los materiales digitales necesitan una infraestructura técnica de servidores, sistemas de almacenamiento y software de gestión no sólo para su preservación, sino simplemente para permitir su consulta y su gestión.

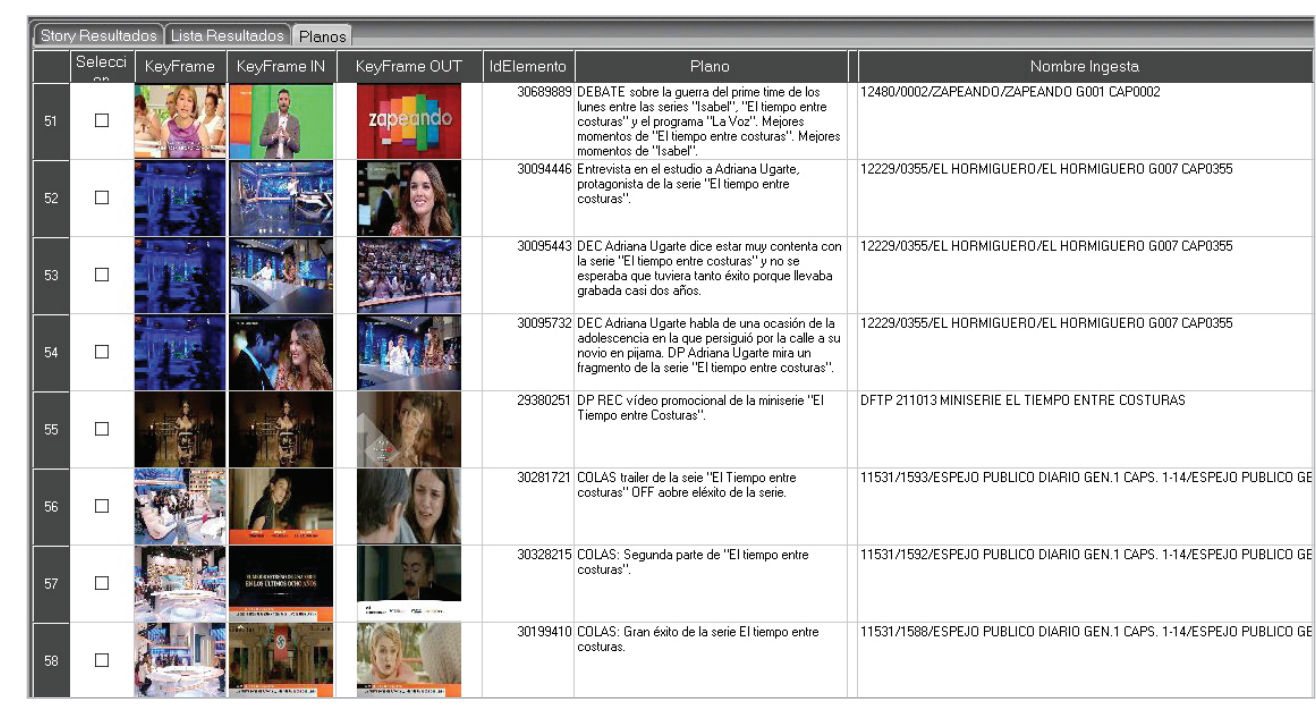

Figura 1. Interfaz de consulta del gestor documental Gama, de Atresmedia, en el que se combinan elementos visuales y textuales procedentes del análisis documental 


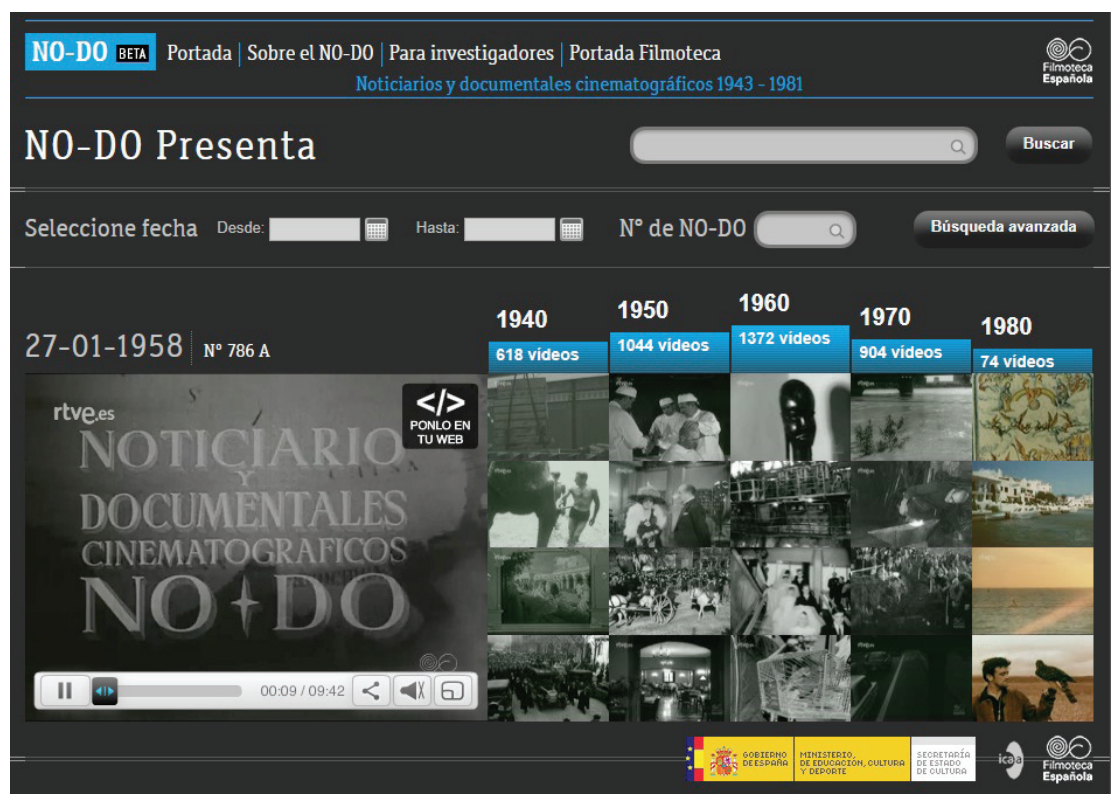

Figura 2. El No-Do online, un caso de éxito en digitalización y acceso público de fondos documentales audiovisuales identidad cultural, lo que permite derivar fondos estatales a proyectos concretos de recuperación y digitalización de archivos de imágenes en peligro de deterioro. ¿Sería posible un modelo similar a nivel nacional o autonómico en España?

Puede afirmarse que muchos fondos audiovisuales permanecen en sus soportes originales y por tanto su acceso público es restringido. En este sentido la digitalización no ha incidido sustancialmente en la constitución de una memoria cultural colectiva, sino que ha permitido a determinados archivos satisfacer de un modo más eficaz la demanda de la industria audiovisual (Nachreiner, 2009). Si consideramos que en estos archivos se conserva el reflejo y testimonio de los últimos cien años de la historia de la humanidad (Hidalgo-Goyanes, 2013), la carencia

Aparte de las grandes corporaciones y organizaciones, que como hemos visto han encauzado sus respectivos procesos de digitalización, si consideramos el resto de archivos audiovisuales susceptibles de digitalización, el panorama nacional es preocupante. Las dificultades son de dos tipos:

- Por un lado la ausencia de un inventario nacional de archivos audiovisuales hace difícil la cuantificación de fondos documentales susceptibles de digitalización. Se sabe que existen centenares, si no miles, de archivos alojados en empresas, fundaciones, pequeñas organizaciones de todo tipo o incluso particulares, pero no cuáles son, qué fondos tienen y en qué soportes.

- Por otro, en muchos casos se trata de archivos que no forman parte esencial de la actividad de la organización, lo que añade dificultades para su identificación y aumenta el riesgo de que las condiciones de conservación en que se encuentren no sean las mejores.

\section{La ausencia de un inventario nacional de archivos audiovisuales hace difícil la cuantificación de fondos susceptibles de digitalización}

Asumiendo que en algún momento pueda realizarse este inventario, se necesitan recursos humanos para identificar contenidos, descartar copias, clarificar derechos de autor y operar los dispositivos de digitalización; también software y hardware de digitalización más los almacenamientos principales y de redundancia correspondientes. ¿Habrá recursos económicos para acometer su digitalización? ¿Quién asumirá este coste? Y, como apuntábamos antes en el caso RTVV ¿cuánto puede esperarse antes de que el deterioro de estos soportes haga su contenido irrecuperable?

Algunos países latinoamericanos como Colombia, Brasil y México, entre otros, han encauzado la preservación del patrimonio audiovisual dentro de un concepto más amplio de de un organismo nacional y una legislación que garanticen su preservación y acceso público representa un problema de urgente resolución.

Para terminar, mencionaremos dos aspectos de obsolescencia que afectan a los documentos grabados en formato $4: 3$ y SD (standard definition). En el primer caso se trata de una relación de aspecto o proporción entre altura y anchura que ya no coincide con el nuevo formato de 16:9 impuesto por la televisión en alta definición. En los archivos de todo el planeta se alojan centenares de miles de imágenes en 4:3 que, al visualizarse en dispositivos configurados para 16:9, muestran dos características franjas negras salvo que en edición se realice un ensanchamiento artificial de la imagen. En el caso de la SD se aprecia una pérdida sustancial de calidad cuando se combinan estas imágenes con las producidas directamente en los nuevos parámetros de la alta definición (HD).

Estas formas de obsolescencia afectan fundamentalmente a las nuevas producciones audiovisuales que utilizan material de archivo, y son más tolerables por el consumidor de estos productos cuando el valor de estas imágenes de archivo destaca más como testimonio histórico que como imágenes de recurso. En este último caso los archivos se ven obligados a renovar sus fondos documentales con imágenes grabadas en los nuevos estándares de producción.

\section{Metadatos, un patrimonio corporativo de generación semiautomática}

La extensión imparable en el acceso a documentos audiovisuales por el gran público y la necesidad de localizarlos en el universo casi infinito de la Red han terminado por popularizar conceptos y prácticas antes restringidos al ámbito de los gestores de información. Términos como indexación, palabra clave o metadatos, pertenecen ya más al mundo multidisciplinar de la información audiovisual que al de la gestión documental, y nadie duda hoy de que los metadatos son un componente patrimonial de los archivos de imágenes.

Podemos diferenciar dos niveles de metadatos asociados al 

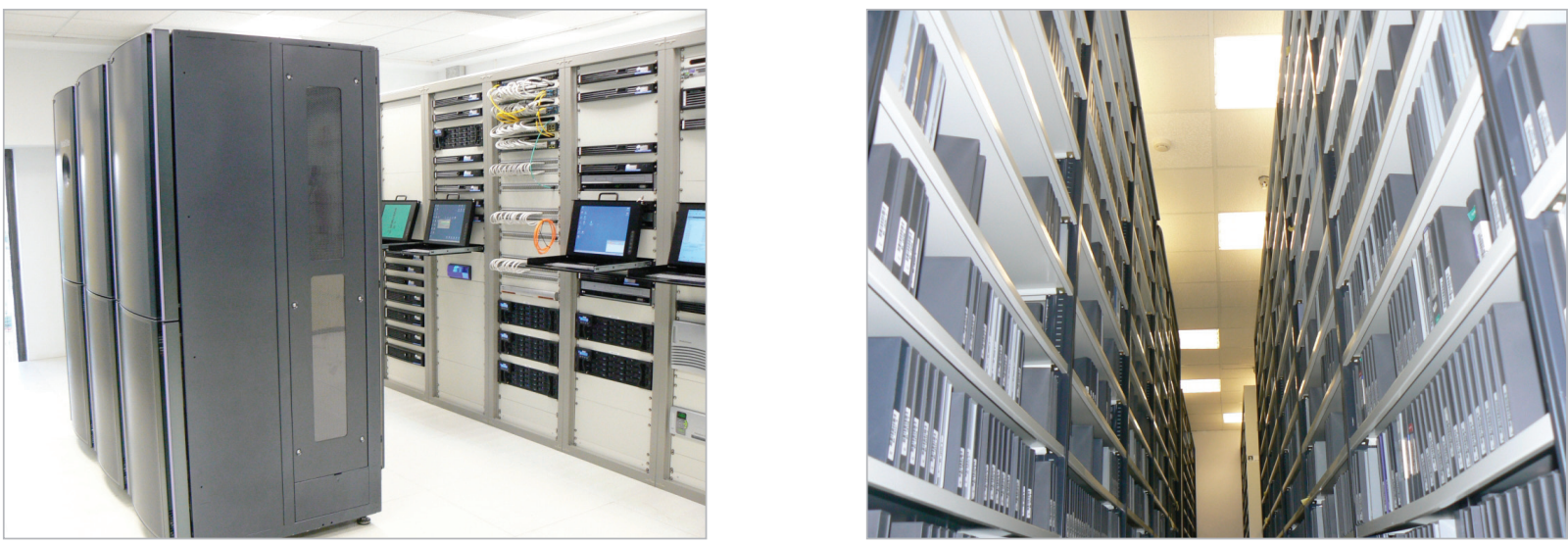

Figura 3. Tras el cierre de RTVV, el futuro del archivo, parcialmente digitalizado, se encuentra todavía sin determinar

documento audiovisual, ya se trate de la indexación y descripción de piezas completas de video o de la descripción de los diferentes planos de los que se componen. Ambos niveles corresponden también a diferentes necesidades de búsqueda y consumo, y en consecuencia también de niveles de gestión.

En el primer caso es donde se ha producido un aumento exponencial tanto de publicación como de consumo, con YouTube como máximo exponente. Su blog oficial afirmaba en mayo de 2013 que se subían al sitio más de 100 horas de nuevo contenido por minuto y que más de mil millones de personas accedían mensualmente a su web. Organizaciones y particulares suben estos contenidos unidos a una sencilla capa de metadatos a base de título, palabras clave, duración y otros datos técnicos de utilidad. Esta sencilla estructura existe también en los CMS de organizaciones y empresas que administran y publican contenidos audiovisuales en sus webs, frecuentemente añadiendo un breve resumen del contenido.

La gestión de esta capa documental de datos normalmente se da en el origen de la creación o la publicación de los contenidos, y no es frecuente que se asuma por documentalistas o gestores de información en las organizaciones. Las razones son evidentes:

- la propia lógica funcional que convierte el proceso de creación, indexación y publicación de contenidos en una dinámica continua realizada por la misma persona;

- la dificultad de mantener colectivos profesionales específicos para una tarea tan concreta y un volumen tan ingente de producción.

Los resultados no parecen decepcionantes en cuanto a eficacia se refiere. En un estudio comparativo entre YouTube y el National Film and Sound Archive (NFSA) como fuentes para los interesados en programas de televisión australianos, se afirmaba, entre otras conclusiones, que la catalogación de los materiales en YouTube era más fiable que la ofrecida por las bases de datos profesionales del NFSA y que la búsqueda era más intuitiva que en éstas, aunque NFSA proporcionaba mayor información sobre datos y fechas de producción (Mckee, 2011).

Otro ámbito muy diferente es el de la gestión documental vinculada a la producción de contenidos para el mercado broadcast, si bien no pasará mucho tiempo antes de que ambos entornos confluyan en cuanto a técnicas de tratamiento documental y búsqueda se refiere. En todo caso, en la actualidad estas técnicas alcanzan su máximo desarrollo en los operadores de televisión.

En líneas generales podemos afirmar que la digitalización ha aportado a los procesos documentales en televisión la posibilidad de incluir metadatos visuales estáticos (key frames o fotogramas representativos) y dinámicos, mediante el acceso a las réplicas en baja resolución de los contenidos digitalizados durante la búsqueda. Los primeros pueden ser seleccionados de forma manual pero es habitual el uso de herramientas de segmentación automática por criterios parametrizables como la detección de cambios de plano, patrones de formas y colorimetría, o simplemente secuencias temporales.

Para contrarrestar la ambigüedad del lenguaje y proporcionar una interfaz funcional al usuario final, son imprescindibles herramientas que interpreten las estructuras lingüísticas en un contexto semántico

Esto ha permitido restar exhaustividad en la descripción del contenido de los planos durante el análisis documental, pero dada la falta de automatismos que interpreten el contenido de una imagen en movimiento, la descripción textual es hoy por hoy imprescindible. Se mantiene así la dependencia, en los sistemas documentales de televisión, de herramientas que permitan interpretar en las búsquedas las cadenas lingüísticas del texto libre utilizadas para la descripción de las imágenes, lo que aumenta su complejidad y explica las diferencias de rendimiento para el usuario final en comparación con la indexación de unidades completas de contenido mediante palabras clave y términos representativos del título.

En consecuencia, el tratamiento documental de imágenes sigue siendo una tarea extremadamente costosa en recursos humanos, con ratios de dedicación en horas de actividad de dos, tres o incluso más veces la duración del material tratado. Esta situación deriva en la práctica en una paradoja de difícil resolución. Por un lado los volúmenes de producción audiovisual aumentan exponencialmente como producto de la multiplicación de los canales de distribución y emisión, lo que incide en un aumento proporcional de la necesidad de recuperar fragmentos audiovisuales según su contenido 
en \&ด̆l Waiscla? pro

Man bijt hond Woordentikkertje Al 766.674 tags ingevoerd en $\mathbf{3 8 0 . 9 6 4}$ matches gemaakt

Speel Woordentikkertie en maak zo het archief van Man bit hond beter doorzoekcaar.

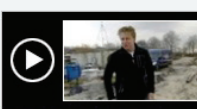

Van keet tot droomhuis 177 keer gespeeld
hoogste score: 12.895

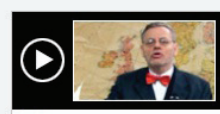
Tolk speeld

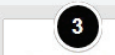

Doen anderen dat ook, dan heeft u een to of in de wachtri een video uit
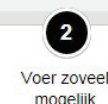
woorden in u ziet of hoor

Om mee te kunnen doen moet $\mathrm{u}$ de $\mathrm{N}$

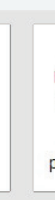
match die punten oplever

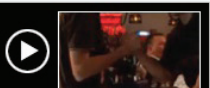

NK armworstelen 41 keer gespeeld
hoogste score: 5.305

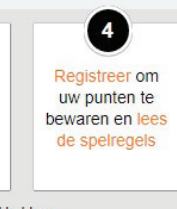
in geinstalleerd hebben.

-

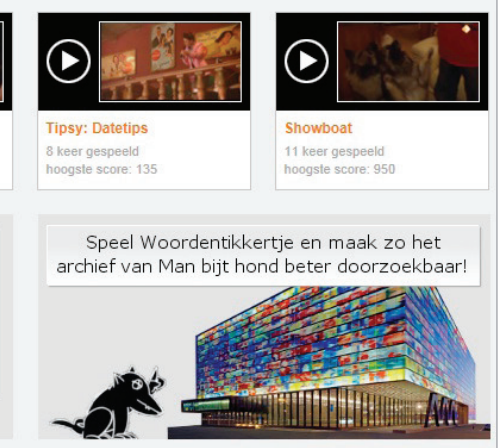

Figura 4. Página del proyecto Waisda, iniciativa de indexación colaborativa del Institute for Sound and Vision enfocada como juego online

temático para alimentar la creciente demanda de producción. Por otro, los recursos humanos dedicados a la gestión de los archivos no aumentan en proporción, sino que se ven reducidos en sintonía con la tendencia de contracción general propia de los períodos de crisis (Giménez-Rayo, 2013).

En este contexto están surgiendo en el mercado herramientas orientadas a la recuperación de información audiovisual basadas en automatismos para interpretar el contenido de los planos buscados. Una alternativa es la extracción automática de la información contenida en los canales de audio y su transcripción a texto, lo que eliminaría la descripción manual de las imágenes si bien derivaría en un producto final aún basado en estructuras lingüísticas (Tuytelaars, 2012).

Aunque se lleva más de una década investigando en este campo y se han implementado soluciones satisfactorias sobre todo en servicios de interacción telefónica o incluso subtitulado de contenidos, su aplicación en sustitución de la descripción documental manual no es todavía integral. Se han obtenido buenos resultados con documentos audiovisuales prioritariamente basados en lo que se denomina "busto parlante", documentos en los que los elementos predominantes son planos medios de personas hablando a cámara en un discurso continuado y uniforme. Es el caso de la información parlamentaria, intervenciones de los presentadores de informativos, o entrevistas unipersonales. Cuando el número de personas aumenta y se superponen las intervenciones, como por ejemplo en una tertulia, o en programas de contenidos diversos y frecuentes cambios de plano, los resultados no son satisfactorios.

Las técnicas de reconocimiento de voz y rastreo de datos en general están siendo también muy utilizadas con fines comerciales para el análisis transmedia y la detección de información aparecida en las agencias de noticias, medios de comunicación y redes sociales en general. Algunas empresas ofrecen estos servicios complementados con valoraciones de "análisis del sentimiento" mediante la detección de contextos semánticos favorables o desfavorables sobre un determinado concepto o marca.

Se asume por tanto que en la actualidad los sistemas de gestión documental de materiales audiovisuales necesitan in1 speler nu onlin

cluir un importante volumen de información textual descriptiva de las imágenes, y que esta información no es generada exclusivamente por los profesionales de la catalogación de imágenes. Bien mediante tecnologías de reconocimiento de voz, bien por la importación de esta información de las mismas fuentes de donde proceden o se crean los contenidos, lo cierto es que se trata de una información muy heterogénea y sometida a las ambigüedades del lenguaje.

Para contrarrestar esta ambigüedad del lenguaje y proporcionar una interfaz funcional al usuario final, resultan imprescindibles herramientas que interpreten las estructuras lingüísticas en un contexto semántico. Algunas aplicaciones permiten la extracción automática de términos y entidades con los que pueden construirse posteriormente universos ontológicos que permitan la desambiguación, por ejemplo, en la búsqueda de personas, o el establecimiento de vínculos semánticos entre términos. El establecimiento de estas relaciones temáticas entre conceptos, como por ejemplo la vinculación entre crisis, desempleo y violencia callejera, es una tarea compleja que sin embargo abre la puerta a modelos colaborativos entre organizaciones y permite construir universos semánticos transparentes para el usuario.

Complementariamente, las búsquedas ejecutadas en lenguaje natural necesitan también de una capa de software que interprete las relaciones lingüísticas entre los términos incluidos en un minutado o una descripción documental. Y no sólo para salvar las dificultades de la sinonimia, metonimia y otras fórmulas semánticas, sino para que la interpretación automática del propio posicionamiento lingüístico de los términos durante la estrategia de búsqueda, pueda reemplazar a la inclusión de descriptores de forma manual durante la catalogación.

Otras investigaciones se orientan a la utilización de fotogramas destacados del contenido como elementos de búsqueda, mediante técnicas de aprendizaje automático a través de las operaciones secuenciales de búsqueda de los usuarios del sistema, o bien proponiendo previamente unos patrones de imágenes como descriptores visuales con los que construir las estrategias de búsqueda. Por ejemplo, unas vacas pastando en un campo, un torso desnudo o una mesa dispuesta para comer.

Un estudio realizado en 2010 en el Netherlands Institute for Sound and Vision concluía que ninguna de las técnicas mencionadas puede todavía reemplazar en solitario la catalogación manual basada en la descripción de planos, si bien cada una de ellas incrementa sustancialmente los resultados de esta catalogación manual (Huurnink et al., 2010). El estudio concluía con la recomendación de priorizar las inversiones en sistemas de reconocimiento de texto y asegurando que la implementación de cualquier sistema basado en la 
recuperación automática del contenido audiovisual pasará necesariamente por la transformación de las interfaces de búsqueda y la forma de construir la estrategia de interrogación. Es decir, no sólo habrá que modificar el sistema de indización, sino también el hábito de búsqueda.

Otras iniciativas para mejorar o completar la indexación de los documentos de un archivo online han buscado la participación del usuario final. Hablamos de la indización colaborativa o social tagging. En 2012 el departamento de consultoría INA Expert del Institut National de l'Audiovisuel, Francia, lanzó una encuesta sobre ejemplos de interacción social dirigida a más de 200 organizaciones en 30 países, cuyas conclusiones fueron parcialmente mostradas en un seminario celebrado en Chile a finales de 2013 (Malherbe; Teruggi, 2013; Varra, 2013). El tercer y cuarto puesto de participación detectado según nivel de implicación fue la re-documentación y el etiquetado, uno de cuyos objetivos es salvar las diferencias semánticas entre el vocabulario de los profesionales y de los usuarios. Sin embargo se trata en realidad de prácticas cuyos resultados redundan en el refuerzo del valor de marca, el incremento de la visibilidad de las colecciones y del marketing en general, más que en una modificación sustancial de las políticas de catalogación y gestión documental en los archivos.

Es el caso del proyecto Waisda (What's that? en holandés) del Institute for Sound and Vision holandés, un juego colaborativo en el que se han añadido más de 760.000 etiquetas en 380.000 jugadas disputadas entre dos usuarios, y en las que se obtiene diferentes puntuaciones por coincidencia de etiquetas con el oponente o inclusión de nombres propios. $\mathrm{O}$ los proyectos Help us tag records in our collection, ofrecido por The National Archives en el Reino Unido, y Your paintings, iniciativa de la Public Catalogue Foundation, la $B B C$ y los museos británicos, en este caso sobre imágenes de obras de arte y en el que se añadieron más de 4.400 .000 etiquetas a un total de 23.217 obras, sólo el $10 \%$ más conocido del total de más de 211.000 obras presentadas en el proyecto. http://woordentikkertje.manbijthond.nl http://discovery.nationalarchives.gov.uk/SearchUl/all-tags/ how-to

http://www.bbc.co.uk/arts/yourpaintings

\section{Hibridación de funciones interprofesionales: una hipótesis cuestionada}

En diciembre de 2012 existían en Europa 3.841 canales de televisión regionales y locales, y 6.130 canales de ámbito nacional e internacional, de los cuales casi 300 están en España. El consumo medio de televisión en nuestro país fue de 239 minutos diarios en ese año, a lo que hay que añadir 21 millones de consumidores únicos de videos online y más de 3.500 millones de videos mensuales visionados con una duración media de 6,7 minutos (Council of Europe, 2012). Internet y las posibilidades de consumo multipantalla han permitido además que los usuarios tengan un papel más activo y puedan escoger los contenidos que desean consumir en cualquier momento y lugar, con dispositivos estimuladores del consumo como el smartphone y la tablet. El $75,3 \%$ de los internautas accede a videos online y en torno al 30\% descarga películas y series o las ve online sin descargar (Larrañaga, 2013). Un 33\% de los internautas españoles revisan la actividad de sus contactos incluyendo fotos, videos o noticias, y el $20 \%$ y el $14 \%$ respectivamente accede a videos o música y publica contenidos audiovisuales, entre otros (Elogia/IAB, 2013). YouTube ocupa el tercer puesto en tiempo dedicado, detrás de Facebook y Twitter, y es, con Facebook, la red social más valorada.

La rotundidad de estas cifras, que son claro testimonio de la envergadura del mercado y la industria audiovisual, no parece trasladarse a la actividad que podría estar desarrollándose de forma proporcional para la gestión documental de todo este volumen de contenidos. Las razones han sido ya parcialmente expuestas:

- en el origen está la mayor versatilidad de los sistemas de producción digital, que traslada algunas de las funciones tradicionales de los archivos al usuario final, como la inserción de metadatos y la búsqueda;

- muchos contenidos completan su ciclo de vida desde la producción a la distribución online, dentro de plataformas administradas directamente por departamentos de redacción multimedia que se nutren de profesionales procedentes de otras titulaciones;

- las ya mencionadas dinámicas empresariales de reducción de plantillas y externalización de servicios, que no propician precisamente un alza en la generación de empleo.

La gestión de contenidos audiovisuales se ha integrado en la actividad y en las dinámicas organizativas diarias de muchas organizaciones, de modo que tareas monográficas como el tratamiento y la gestión documental de materiales audiovisuales al servicio de otras áreas de producción sólo conservan su plena vigencia en organizaciones donde la generación de contenidos es parte esencial de la actividad, como en las empresas de televisión, o se dedican a la preservación y difusión, como es el caso de las filmotecas.

Se presenta así un dilema que está teniendo un eco recurrente en foros y encuentros entre profesionales. Se observa que existe una distancia entre los planes académicos de las titulaciones en biblioteconomía y documentación, orientados monográficamente a la gestión de información, y los perfiles profesionales demandados desde determinados sectores, como el multimedia, donde la gestión de información no ocupa un lugar independiente sino integrado en otras actividades de la organización.

Así, la hipótesis de una posible hibridación entre diferentes perfiles profesionales que permita un transvase bidireccional o multidireccional de tareas no parece estar produciéndose. Esta hipótesis contemplaba la posibilidad de que un nuevo profesional multitarea pudiera integrarse en la cadena de producción, gestión y distribución de contenidos audiovisuales desde diferentes titulaciones, incluyendo las de biblioteconomía y documentación. Sin embargo, existe riesgo de que este trasvase sea mayoritariamente unidireccional, es decir que suponga una merma de las funciones tradicionales de los gestores de información en favor de otros colectivos que tienen un lugar más consolidado en el entorno multimedia. 


\section{Conclusiones}

- El proceso de digitalización de la producción audiovisual se ha completado a todos los niveles, tanto en los grandes operadores como en los pequeños productores de contenidos.

- La digitalización retrospectiva de los grandes archivos audiovisuales progresa en líneas generales, pero no ocurre así con el resto de archivos audiovisuales de España. El acceso público a este tipo de contenidos sigue siendo una asignatura pendiente.

- Los sistemas automáticos de tratamiento documental para materiales audiovisuales no parecen completar su implantación en producción.

- En un entorno de crecimiento exponencial de la información audiovisual, se percibe más una tendencia unidireccional hacia la pérdida de posicionamiento de los profesionales de la documentación que hacia una hibridación multidireccional de funciones y perfiles profesionales.

\section{Bibliografía}

Alfonso-Noguerón, Lola (2009). “De la videoteca al robot pasando por Tarsys. Nuevos sistemas de gestión multimedia en Radiotelevisión Valenciana". El profesional de la información, v. 18, n. 3, pp. 333-340.

http://www.elprofesionaldelainformacion.com/ contenidos/2009/mayo/12.pdf

http://dx.doi.org/10.3145/epi.2009.may.12

Caldera-Serrano, Jorge; Arranz-Escacha, Pilar (2012). Documentación audiovisual en televisión. Barcelona: editorial UOC, colección El profesional de la información, n. 13, 116 pp. ISBN: 9788490299821

Conesa, Alicia (2012). “De la videoteca a l'arxiu digital: evolució del Departament de Documentació de Televisió de Catalunya". Trípodos, n. 31, pp. 99-108.

http://www.raco.cat/index.php/Tripodos/article/ viewFile/262075/349257

Council of Europe (2012). European audiovisual observatory yearbook. ISBN: 9789287176059

De-Prado, José-María (2013). "Spanish NO-DO Online". En: Cinema Expert Group/Subgroup Film Heritage - Meeting of 27/28 November.

http://ec.europa.eu/information_society/newsroom/cf/ dae/document.cfm?doc_id=3829

Elogia/IAB (2013). IV Estudio anual redes sociales. Elogia Marketing 4ecommerce, IAB Spain research, $67 \mathrm{pp}$.

Giménez-Rayo, Mabel (2012). "La documentación audiovisual en televisión en el mundo 2.0: retos y oportunidades". Trípodos, n. 31, pp. 79-97.

http://www.tripodos.com/index.php/Facultat_ Comunicacio_Blanquerna/article/view/39

González-Ruiz, David; Térmens, Miquel; Ribera, Mireia (2012). "Aspectos técnicos de la digitalización de fondos audiovisuales". El profesional de la Información, v. 21, n. 5, pp. 520-528. http://eprints.rclis.org/17740

http://dx.doi.org/10.3145/epi.2012.sep.12

Hidalgo-Goyanes, Paloma (2013). "Prevenir la amnesia colec- tiva: el acceso público a los archivos de televisión". Documentación de las ciencias de la información, v. 36, pp. 143-166. http://revistas.ucm.es/index.php/DCIN/article/view/42946

Huurnink, Bouke; Snoek, Cees G. M.; De-Rijke, Maarten; Smeulders, Arnold W. M. (2010). "Today's and tomorrow's retrieval practice in the audiovisual archive". En: ACM Intl conf on image and video retrieval.

http://staff.science.uva.nl/ mdr/Publications/Files/ civr2010-huurnink.pdf

Larrañaga, Julio (2013). “La demanda de televisión en multipantallas". Documentación de las ciencias de la información, v. 36, pp. 191-208.

https://revistas.ucm.es/index.php/DCIN/article/view/42105

Lizarralde, Koldo (2009). “Media asset management (MAM) y plataformas de digitalización de contenidos de ETB (transcripción de la ponencia)". En: Dokumentazio zerbitzuak Euskal Herriko komunikabideetan / Los servicios de documentación en los medios de comunicación del País Vasco. Euskal Herriko Unibertsitatea / Universidad del País Vasco, pp. 159-181.

http://eprints.rclis.org/15788

López-de-Quintana-Sáenz, Eugenio (2007). “Transición y tendencias de la documentación en televisión. Digitalización y nuevo mercado audiovisual". El profesional de la información, v. 16, n. 5, pp. 397-408.

http://www.elprofesionaldelainformacion.com/ contenidos/2007/septiembre/01.pdf http://dx.doi.org/10.3145/epi.2007.sep.01

López-de-Quintana-Sáenz, Eugenio (2013). “Atresmedia: la memoria audiovisual al servicio de la producción de contenidos". En: Documentació digital i memòria històrica: caçant fantasmes?, VII Jornades de l'Associació d'Arxivers i Gestors de Documents Valencians, Revista d'arxius, n. 11-12, pp. 171-184.

Malherbe, Clément; Teruggi, Daniel (2013). “Herramientas para la indización automática, la búsqueda y la interacción social". En: Nuevos retos en la gestión de archivos audiovisuales y contenidos digitales, Santiago de Chile, 19-21 de noviembre.

McKee, Alan (2011). "YouTube versus the National Film and Sound Archive: which is the more useful resource for historians of Australian television?". Television and new media, v. 12 , n. 2, pp. 154-173.

http://dx.doi.org/10.1177/1527476410365707

Nachreiner, Thomas (2009). "The digitization of audiovisual archives. Technological change within the structures of reproduction". En: Riha, Daniel; Mak, Anna. Digital memories: exploring critical issues. Interdisciplinary Press, pp. 149-158.

Tuytelaars, Tinne (2012). "Content-based analysis for accessing audiovisual archives: alternatives for concept-based indexing and search". En: $13^{\text {th }}$ Int $/$ workshop on image analysis for multimedia interactive services (Wiamis 2012).

Varra, Jean (2013). "Digitization of audiovisual archives and management of digital media". En: Nuevos retos en la gestión de archivos audiovisuales y contenidos digitales, Santiago de Chile, 19-21 de noviembre. 